\title{
Impact of office hysteroscopy in repeated implantation failure: Experience of a single center
}

\author{
Emre Göksan Pabuçcu' ${ }^{1}$ İbrahim Yalçın², Taylan Bodur ${ }^{3}$, Gamze Sinem Çağlar ${ }^{1}$, Recai Pabuçcu ${ }^{1,4}$ \\ ${ }^{1}$ Department of Obstetrics and Gynecology, Ufuk University School of Medicine, Ankara, Turkey \\ ${ }^{2}$ Department of Obstetrics and Gynecology, Zekai Tahir Burak Women's Health and Research Hospital, Ankara, Turkey \\ ${ }^{3}$ Department of Obstetrics and Gynecology, Yücelen Muğla Hospital, Muğla, Turkey \\ ${ }^{4}$ Centrum Clinic Women's Health and ART Centre, Ankara, Turkey
}

\begin{abstract}
Objective: Repeated implantation failure (RIF) is a clinical entity affecting many couples undergoing assisted reproductive technology (ART). Various intrauterine pathologies contribute to RIF. Nevertheless, vaginal sonography and hysterosalpingography, which are the common diagnostic tools for the initial follow-up, have limited sensitivities. In this context, we aimed to evaluate the impact of office hysteroscopy (oHS) on live birth rates (LBRs) when performed prior to subsequent ART cycles in women with a history of RIF.

Material and Methods: The database of an assisted reproduction center was retrospectively reviewed to detect eligible cases. A total of 363 women out of 2875 admissions were consecutively included in the analysis, of which 119 formed the oHS group and 244 formed the non-oHS group prior to a new ART cycle. Women in the oHS arm were examined during their early follicular phase via a vaginoscopic approach 1-6 months before the beginning of a new cycle. The standard in-vitro fertilization-intracytoplasmic sperm injection (IVF/ICSI) cycle was applied to all the women.

Results: In the oHS group ( $\mathrm{n}=119), 61$ patients had intrauterine abnormalities, with an overall abnormality rate of $51.2 \%$. Implantation, pregnancy, and LBRs of the groups were statistically similar. LBRs of the women with abnormal oHS findings (15/61, 24.5\%), with normal oHS findings $(14 / 58,24.1 \%)$, and without oHS $(39 / 244,16 \%)$ were statistically similar $(p=0.41)$.

Conclusion: Unrecognized intrauterine pathologies can be easily detected and concurrently treated during oHS with high success rate. However, a beneficial impact depends on the extent of the pathology and thus, routine application to enhance reproductive outcomes is still not warranted. (J Turk Ger Gynecol Assoc 2016; 17: 197-200)
\end{abstract}

Keywords: Endometrium, in-vitro fertilization, office hysteroscopy, pregnancy

Received: 23 September, 2016 Accepted: 17 October, 2016

\section{Introduction}

Repeated implantation failure (RIF) is a distressing clinical entity and refers to a situation when transferred embryo(s) repeatedly fail to implant despite numerous attempts via assisted reproductive technology (ART). Several uterine pathologies, such as polyps, adhesions, septum, or myomas, have been linked with poor reproductive outcomes when detected prior to ART $(1,2)$. Such pathologies have been reported in up to $50 \%$ of women with RIF, leading to suggestions that corrections could improve reproductive outcomes (3). Office hysteroscopy (oHS) is considered as the "gold standard" for assessment of the uterine cavity, which also provides a chance for concurrently treating uterine pathologies. Despite several advantages, the European Society of Human Reproduction and Endocrinology does not recommend routine oHS in women undergoing ART, unless there is an apparent uterine pathology (4). Moreover, two recent randomized controlled trials have failed to show any clear benefit of this procedure either before the first IVF cycle or in repeated failed cycles $(5,6)$.

The present study aimed to evaluate the incidence of unrecognized uterine pathologies with oHS in women with RIF as well as the impact of oHS on live birth rates (LBRs) when performed prior to a new ART cycle.

\section{Material and Methods}

This is a retrospective cohort study of infertile patients who were treated at a private fertility center between 2007 and 2014. As this study was retrospectively designed, institutional review board approval was not obtained. RIF was defined as two or more unsuccessful ART/embryo transfer cycles despite the availability of good quality embryos (7). According to the ART center's policy, all women with a history of RIF were suggested to undergo an oHS procedure preceding a new ovarian stimulation cycle despite normal vaginal sonography (TVS) or hysterosalpingography (HSG). 
Subjects who underwent the procedure formed the oHS group, whereas the remaining subjects formed the non-oHS group. All included patients were between 18 and 40 years of age and had follicle-stimulating hormone (FSH) levels of $<15 \mathrm{IU} / \mathrm{mL}$. The exclusion critertia were 1) poor ovarian response according to the Bologna criteria (8) or women with premature ovarian failure; 2) male subjects with severe oligozoospermia, oligoasthenozoospermia, or azoospermia; 3) preimplantation genetic screening and cryopreserved/thawed embryo transfer cycles; 4) women with confirmed endometriosis; 5) women with hypothalamic amenorrhea; and 6) women who underwent oHS more than 6 months prior to a new cycle.

\section{Office hysteroscopy procedure}

All patients were examined during their early follicular phase, 1-6 months before the start of a new ART cycle, via the vaginoscopic approach as previously described (9). No routine preoperative analgesia, antibiotics, sedation, or cervical preparation was used. Briefly, a rigid hysteroscope (continuous flow; $30^{\circ}$ forward oblique view) with an outer diameter of $4 \mathrm{~mm}$ using $0.9 \%$ normal saline was used. Following adequate distension of the uterine cavity, systematic inspection was performed. Standard gynecologic surgical procedures were used to treat the recognized pathologies, such as removing all polyps and adhesions. A senior physician (R.P.) performed all the procedures.

\section{Ovarian stimulation protocol}

All the couples were subjected to ICSI and all sperm injections were performed with fresh specimens. One ART cycle of each patient was included in the study. All the OS cycles were conducted using the short antagonist protocol either with recombinant (Gonal-F, Merck Serono; İstanbul, Turkey) or with human menopausal gonadotropins (Menogon, Ferring; İstanbul, Turkey) (150-300 IU/day s.c.). Ovarian stimulation, oocyte retrieval, and embryo transfer procedures were performed as described elsewhere (10). Top quality embryos were defined as those with $\geq 7$ evenly sized cells and $\leq 10 \%$ fragmentation on day 3 and with $\mathrm{a} \geq 3$ AA quality of blastocyst morphology on day 5 . During the study period, one embryo was transferred to patients aged $<35$ years, while two embryos were transferred for those $\geq 35$ years, in accordance with the local legislation. Embryo implantation was defined as the proportion of women with an intrauterine gestational sac on an ultrasound scan $\geq 4$ weeks after embryo transfer, with the rate calculated as the number of gestational sacs divided by the number of embryos transferred. The miscarriage rate was defined as the proportion of women with pregnancy loss before 24 weeks of gestation. The pregnancy rate was defined as the proportion of women with a positive quantitative serum human chorionic gonadotropin test 12 days after embryo transfer, while LBR was defined as the delivery of a live fetus beyond 24 weeks of gestation after one ART cycle.

\section{Statistical analysis}

SPSS 22.0 statistical software (SPSS Inc.; Chicago, IL, USA) was used for data analysis. The values of the measurement data are expressed herein as the mean \pm SD when applicable. Between-group differences were compared using the inde- pendent samples t-test. Classified information was statistically analyzed using Pearson's $\chi^{2}$ test, one-way analysis of variance, and Fisher's exact test. Statistical significance was defined as $\mathrm{p}<0.05$.

\section{Results}

A total of 440 RIF cases were detected out of 2875 admissions during the study period, of which 366 met the inclusion criteria. Among those, three women were excluded from the analysis due to operative HS work out, and finally, 363 women were consecutively selected for the analysis, of which 119 formed the oHS group and 244 formed the non-oHS group. The time interval between oHS and a new ART cycle was 1-6 months and during this period, the procedure was the first and only one performed for those in the oHS arm. There were no statistically significant differences between the two groups with regard to demographic properties, basal patient characteristics, and general cycle outcomes, as shown in Table 1, 2, respectively. In the oHS group $(n=119), 61$ patients had intrauterine abnormalities, with an overall abnormality rate of $51.2 \%$. The types and incidence of abnormalities were mild intrauterine and cervical adhesions (25/61, 40.9\%), endometrial polyps (23/61, 37.7\%), polypoid endometrium (11/61, 18.1\%), and arcuate uterus (2/61, 3.2\%).

According to the reproductive outcomes, implantation, pregnancy, and LBRs of the groups were statistically similar (Table 3). LBRs of the women with abnormal oHS findings (15/61, 24.5\%), normal oHS (14/58, 24.1\%), and women without oHS (39/244, 16\%)

Table 1. Basal patient characteristics of the groups

\begin{tabular}{|l|c|c|c|}
\hline Variable & oHS group & Non-HS group & p \\
\hline Age (years) & $30.7 \pm 5.3$ & $31.93 \pm 4.4$ & 0.52 \\
\hline Duration of infertility (years) & $6.94 \pm 3.72$ & $7.83 \pm 3.47$ & 0.39 \\
\hline AFC (in both ovaries) & $8.3 \pm 3.0$ & $8.66 \pm 2.43$ & 0.47 \\
\hline $\begin{array}{l}\text { Number of previous ART } \\
\text { attempts }\end{array}$ & $4.04 \pm 1.5$ & $4.06 \pm 1.21$ & 0.89 \\
\hline $\begin{array}{l}\text { AFC: antral follicle count; ART: assisted reproductive technology; oHS: } \\
\text { office hysteroscopy; non-HS: non-hysteroscopy } \\
\text { Results are given in terms of the mean ( } \pm \text { SD). }\end{array}$ \\
\hline
\end{tabular}

Table 2. Cycle characteristics of the groups

\begin{tabular}{|c|c|c|c|}
\hline Variable & oHS group & Non-HS group & $\mathbf{p}$ \\
\hline $\begin{array}{l}\text { Total gonadotropin dosage } \\
\text { (IU) }\end{array}$ & $2318 \pm 800$ & $2556 \pm 941$ & $0.01 *$ \\
\hline Total stimulation days, $\mathrm{n}$ & $10.92 \pm 1.92$ & $10.76 \pm 2.48$ & 0.56 \\
\hline Peak endometrial echo (mm) & $11.4 \pm 1.8$ & $10.6 \pm 1.4$ & 0.46 \\
\hline No of retrieved oocytes, $n$ & $9.04 \pm 4.36$ & $8.21 \pm 5.03$ & 0.12 \\
\hline No of transferred embryos, $n$ & $1.63 \pm 0.58$ & $1.61 \pm 0.62$ & 0.70 \\
\hline Fertilization rate (\%) & $67.3 \pm 20.7$ & $63.37 \pm 25.02$ & 0.38 \\
\hline \multicolumn{4}{|c|}{$\begin{array}{l}\text { oHS: office hysteroscopy; non-HS: non-hysteroscopy } \\
\text { Results are given in terms of the mean }( \pm \mathrm{SD}) . \\
* \mathrm{p}<0.05 \text {. }\end{array}$} \\
\hline
\end{tabular}


Table 3. Reproductive outcomes of the groups

\begin{tabular}{|l|c|c|c|}
\hline & $\begin{array}{c}\text { oHS group } \\
(\mathbf{1 1 9 )}\end{array}$ & $\begin{array}{c}\text { Non-HS group } \\
\mathbf{( 2 4 4 )}\end{array}$ & $\mathbf{p}$ \\
\hline Implantation rate (\%) & $22.39 \pm 39.86$ & $18.70 \pm 36.57$ & 0.38 \\
\hline Positive hCG, n (\%) & $41(34.4)$ & $63(25.8)$ & 0.08 \\
\hline LBR/ET, n (\%) & $29(24.3)$ & $39(15.9)$ & 0.06 \\
\hline Miscarriages, n (\%) & $10(8.4)$ & $18(7.3)$ & 0.26 \\
\hline
\end{tabular}

hCG: human chorionic gonadotropin; LBR: live birth rate; oHS: office hysteroscopy; non-HS: non-hysteroscopy; ET: embryo transfer Results are given in terms of the mean $( \pm \mathrm{SD})$.

were statistically similar $(p=0.41)$. There were no complications encountered during or after the procedure in women who underwent oHS.

\section{Discussion}

According to our results, oHS prior to a new OS cycle does not improve LBRs in women with RIF. A slightly higher LBR was noted in the oHS group without reaching statistical significance. In routine practice, TVS and HSG are the main tools to document the uterine texture prior to ART; however, the diagnostic accuracies of these are quite low with limited sensitivities and specificities (11-14). Diagnostic limitation is likely to be more prominent in those with a history of RIF, as the frequency of unrecognized pathologies may be up to $50 \%(2,15)$. In the study by Gao et al. (16), nearly $80 \%$ of intrauterine abnormalities were found to be undiagnosed with HSG or TVS in those with RIF. This rate is approximately $50 \%$ in our data. As all the women in the oHS arm underwent their first oHS procedure in our study, the prevalence of abnormalities was considered to be relatively high. It seems that a considerable number of RIF cases are somehow misdiagnosed as having "normal" uterine texture for a period of time, unless oHS is performed prior to a new cycle. All the given data justify the need for oHS despite normal findings on TVS or HSG in RIF cases.

One of the most beneficial impacts of oHS is the correction of specific uterine cavity abnormalities when detected. Endometrial polyps and different degrees of adhesions are the most common findings in women with RIF in the literature and in our data as well $(2,17)$. Adhesions are likely to be unrecognized with TVS during initial follow-up, and they should be better removed when detected in order to maintain successful implantation (18-20). Endometrial polyps are quite common and have been shown to compromise pregnancies, depending on the size, by interfering with embryo implantation (21). It has been shown that polypectomy prior to IVF, even for small polyps $(<2 \mathrm{~cm})$, might improve the take-home baby rate in patients undergoing IVF (22). Thus, the routine removal of polyps prior to a new ART attempt is also suggested (21). Despite previous data underlining the beneficial impact of correcting unsuspected uterine cavity abnormalities, a very recent TROPHY trial failed to demonstrate such an impact (5). This might be explained with the fact that they identified cervical or uterine cavity abnormalities only in $26 \%$ of women and two- thirds of those were not treated. In our data, apparent polyps and adhesions were the most common findings, and $40 \%$ of the women in the oHS group were treated.

It has been shown that the fertility-enhancing effect of oHS could also be independent from the correction of intrauterine abnormalities. Hysteroscopy has been proposed to improve ART outcomes through an endometrial injury process leading to embryo implantation $(23,24)$. The outcomes of the women in the oHS arm without any pathologic findings being generally more favorable compared to those without oHS in our data is speculating this impact. In their meta-analysis, El-Toukhy et al. (1) showed a significant improvement in the outcome of the normal hysteroscopy subgroup compared to in controls $(\mathrm{RR}=1.63,95 \%$ CI $1.35-1.98, \mathrm{p}<0.001)$. The time interval between mechanical injury and ET is also speculative to influence pregnancy outcomes. In a recent meta-analysis, endometrial scratching (four studies) or oHS (three studies) was shown to increase the CPRs of women with a history of RIF when induced in the preceding cycle of OS (25). The same favorable results have been reported when oHS was performed within 50 days (13) or even within 6 months prior to a new ART (16). On the other hand, this impact is somehow questionable in light of the recent conflicting evidence $(5,26)$. Further research is still needed to optimize instrumentation and timing.

The limitations of this study are its retrospective design and lack of power analysis. On the other hand, the complete data set was from a single center and the same senior physician performed all the oHS procedures, as this should better overcome interobserver discrepancies. In conclusion, unrecognized intrauterine pathologies can be easily detected and concurrently treated during the oHS procedure with high success rates. However, the overall beneficial impact in terms of reproductive outcomes seems depending on the extent of the pathology.

Ethics Committee Approval: N/A.

Informed Consent: N/A.

Peer-review: Externally peer-reviewed.

Author Contributions: Concept-E.G.P.; Design-E.G.P., G.S.Ç.; Supervision - R.P.; Resources - R.P.; Materials - R.P., G.S.Ç.; Data Collection and/ or Processing - E.G.P., I.Y., T.B.; Analysis and/or Interpretation - E.G.P., G.S.Ç., I.Y.; Literature Search - E.G.P., I.Y., T.B., G.S.Ç.; Writing Manuscript - E.G.P., G.S.Ç.; Critical Review - R.P.

Conflict of Interest: No conflict of interest was declared by the authors.

Financial Disclosure: The authors declared that this study has received no financial support.

\section{References}

1. El-Toukhy T, Sunkara S, Coumarasamy A, Grace J, Khalaf Y. Outpatient hysteroscopy and subsequent IVF cycle outcome: a systematic review and meta-analysis. Reprod Biomed Online 2008; 16: 712-9.

2. Makrakis E, Hassiakos D, Stathis D, Vaxevanoglou T, Orfanoudaki E, Pantos K. Hysteroscopy in women with implantation failures after invitro fertilization: findings and effects on subsequent pregnancy rates. J Minim Invasive Gynecol 2009; 16: 181-7.

3. Moini A, Kiani K, Ghaff ari F, Hosseini F. Hysteroscopic findings in patients with a history of two implantation failures following in vitro fertilization. Int J Fertil Steril 2012; 6: 27-30. 
4. Crosignani PG, Rubin BL. Optimal use of infertility diagnostic tests and treatments. The ESHRE Capri Workshop Group. Hum Reprod 2000; 15: 723-32.

5. El-Toukhy T, Campo R, Khalaf Y, Tabanelli C, Gianaroli L, Gordts SS, et al. Hysteroscopy in recurrent in-vitro fertilisation failure (TROPHY): a multicentre, randomised controlled trial. Lancet 2016; 387: 2614-21.

6. Smit JG, Kasius JC, Eijkemans MJ, Koks CA, van Golde R, Nap AW, et al. Hysteroscopy before in-vitro fertilisation (inSIGHT): a multicentre, randomised controlled trial. Lancet 2016; 387: 2622-9.

7. Polanski LT, Baumgarten MN, Quenby S, Brosens J, Campbell BK, Raine-Fenning NJ. What exactly do we mean by 'recurrent implantation failure'? A systematic review and opinion. Reprod Biomed Online 2014; 28: 409-23.

8. Ferraretti P, La Marca A, Fauser B, Tarlatzis B, Nargund G, Gianaroli L; ESHRE working group on Poor Ovarian Response Definition. ESHRE consensus on the definition of 'poor response' to ovarian stimulation for in vitro fertilization: the Bologna criteria. Hum Reprod $2011 ; 26 ; 1616-24$.

9. El-Mazny A, Abou-Salem N, El-Sherbiny W, Saber W. Outpatient hysteroscopy: a routine investigation before assisted reproductive techniques? Fertil Steril 2011; 95: 272-6.

10. Pabuccu R, Pabuccu EG, Gursoy AY, Caglar GS, Yilmaz MB, Ozdegirmenci O. Improved cycle outcomes after laparoscopic ovarian diathermy in hyper-responder patients with previous ART failure. Gynecol Endocrinol 2014; 30: 881-4.

11. Cunha-Filho J, de Souza C, Salazar C, Facin A, Freitas F, Passos E. Accuracy of hysterosalpingography and hysteroscopy for intrauterine lesions in infertile patients in an assisted-fertilization programme. Gynecologic Endoscopy 2001; 10: 45-8.

12. Grimbizis G, Tsolakidis D, Mikos T, Anagnostou E, Asimakopoulos E, Stamatopoulos $\mathrm{P}$, et al. A prospective comparison of transvaginal ultrasound, saline infusion sonohysterography, and diagnostic hysteroscopy in the evaluation of endometrial pathology. Fertil Steril 2010; 94: 2720-5.

13. Karayalçin R, Ozyer S, Ozcan S, Uzunlar O, Gürlek B, Moraloğlu O, et al. Office hysteroscopy improves pregnancy rates following IVF. Reprod Biomed Online 2012; 25: 261-6.

14. Taskin E, Berker B, Ozmen B, Sönmezer M, Atabekoglu C. Comparison of hysterosalpingography and hysteroscopy in the evaluation of the uterine cavity in patients undergoing assisted reproductive technologies. Fertil Steril 2011; 96: 349-52.
15. Bozdag G, Aksan G, Esinler I, Yarali H. What is the role of office hysteroscopy in women with failed IVF cycles? Reprod Biomed Online 2008; 17: 410-5.

16. Gao M, Sun Y, Xie H, Fang S, Zhao X. Hysteroscopy prior to repeat embryo transfer may improve pregnancy outcomes for asymptomatic women with repeated implantation failure. J Obstet Gynaecol Res 2015; 41: 1569-76.

17. Dicker D, Ashkenazi J, Feldberg D, Farhi J, Shalev J, Ben-Rafael Z. The value of repeat hysteroscopic evaluation in patients with failed in-vitro fertilization cycles. Fertil Steril 1992; 58: 833-5.

18. Soares SR, Barbosa dos Reis MM, Camargos AF. Diagnostic accuracy of sonohysterography, transvaginal sonography, and hysterosalpingography in patients with uterine cavity diseases. Fertil Steril 2000; 73: 406-11.

19. Margalioth EJ, Ben Chetrit A, Gal M, Eldar-Geva T. Investigation and treatment of repeated implantation failure following IVF-ET. Human Reprod 2006; 21: 3036-43.

20. Oliveira F, Abdelmassih V, Diamond M, Dozortsev D, Nagy ZP, Abdelmassih R. Uterine cavity findings and hysteroscopic interventions in patients undergoing in vitro fertilization- embryo transfer who repeatedly cannot conceive. Fertil Steril 2003; 80: 1371-5.

21. Coughlan C, Ledger W, Wang Q, Liu F, Demirol A, Gurgan T, et al. Recurrent implantation failure: definition and management. Reprod Biomed Online 2014; 28: 14-38.

22. Lass A, Williams G, Abusheikha N, Brinsden P. The effect of endometrial polyps on outcomes of in-vitro fertilization (IVF) cycles. J Assist Reprod Genet 1999; 16: 410-5.

23. Demirol A, Gürgan T. Effect of treatment of intrauterine pathologies with office hysteroscopy in patients with recurrent IVF failure. Reprod Biomed Online 2004; 8: 590-4.

24. Kilic Y, Bastu E, Ergun B. Validity and efficacy of office hysteroscopy before in vitro fertilization treatment. Arch Gynecol Obstet 2013; 287: $577-81$.

25. Potdar N, Gelbaya T, Nardo LG. Endometrial injury to overcome recurrent embryo implantation failure: a systematic review and meta-analysis. Reprod Biomed Online 2012; 25: 561-71.

26. Panagiotopoulou N, Karavolos S, Choudhary M. Endometrial injury prior to assisted reproductive techniques for recurrent implantation failure: a systematic literature review. Eur J Obstet Gynecol Reprod Biol 2015; 193: 27-33. 